\title{
A study to assess the effectiveness and perception of students regarding Case Based Learning over traditional teaching method in Community Medicine
}

\author{
Rachana R Annadani ${ }^{1}$, Malatesh Undi ${ }^{2}$
}

${ }^{1}$ Assistant Professor, Department of Community Medicine, Karwar Institute of Medical Sciences, Karwar, Karnataka; ${ }^{2}$ Assistant Professor, Department of Community Medicine, Karwar Institute of Medical Sciences, Karwar, Karnataka

\begin{tabular}{|c|c|c|c|c|c|c|c|c|}
\hline Abstract & Introduction & Methodology & Results & Conclusion & References & Citation & \multicolumn{2}{|c|}{ Tables / Figures } \\
\hline \multicolumn{9}{|c|}{ Corresponding Author } \\
\hline \multicolumn{8}{|c|}{$\begin{array}{l}\text { Dr. Malatesh Undi, Assistant Professor, Department of Community Medicine, Karwar Institute of } \\
\text { Medical Sciences, Karwar, Karnataka - } 581301 \\
\text { E Mail ID: } \underline{\text { malatesh.u@gmail.com }}\end{array}$} & 回部回 \\
\hline
\end{tabular}

\section{Citation}

Annadani RR, Undi M. A study to assess the effectiveness and perception of students regarding Case Based Learning over traditional teaching method in Community Medicine. Indian J Comm Health. 2021;33(1):41-46. https://doi.org/10.47203/IJCH.2021.v33i01.006

Source of Funding: Nil Conflict of Interest: None declared

\section{Article Cycle}

Received: 09/12/2020; Revision: 17/01/2021; Accepted: 27/02/2021; Published: 31/03/2021

This work is licensed under a Creative Commons Attribution 4.0 International License.

\section{Abstract}

Background: Case based learning ( $\mathrm{CBL}$ ) among medical undergraduates, has more interactive sessions and students been involved in thinking, analyzing and interpretation. However, it is not clear if it is reflected in their assessment results. Aim \& Objective: To assess the effectiveness and perception of Case Based Learning over the traditional TL method used in Community Medicine among second year medical undergraduates. Settings and Design: A randomized controlled study was conducted among second year medical undergraduates studying in a government medical college in coastal Karnataka. Methods and Material: 143 Students were randomly allocated into two groups- Group A underwent traditional teaching and Group B underwent Case Based learning. The effectiveness of TL methods was assessed using Multiple Choice Questions (MCQs). Group B's perception regarding CBL was also obtained. Statistical analysis: Inter-group and intra-group mean scores of the pre-test, post-test and retention tests of MCQs of the students were compared using independent t-test and paired t-test respectively. Results: Statistically significant difference was observed in post-test and retention test scores between the groups. Students perceived CBL aroused interest and encouraged self-directed learning. Conclusion: $\mathrm{CBL}$ was effective over the traditional teaching learning method.

\section{Keywords}

Self-directed Learning; Teaching; Perception; Students; Community Medicine

\section{Introduction}

Over the past few years, medical teaching is changing and adapting newer techniques that are students friendly. Active learning activities promote a higher level of learning wherein students control their learning environments and develop interdependent or cooperative relationships with each other. (1) Traditional methods like lectures and small group teaching in the form of tutorials are commonly used teaching methods for higher education like medical education. In these teaching methods, teachers talk more and students may not take active part in discussions or debate.(2) Hence there is a need for self-directed learning among the medical graduates, which makes them more 
INDIAN JOURNAL OF COMMUNITY HEALTH / VOL 33 / ISSUE NO 01 / JAN- MAR 2021 involved in active learning. Case based learning (CBL) is one such method which has more interactive sessions \& students are involved in thinking, analyzing \& interpretation. $(3,4)$

$\mathrm{CBL}$ promotes active learning by utilizing clinical case scenarios which reflect real life experiences that students will face during the clinical phase of their medical education.(5) Cases are generally written as problems that provide students with the history, physical findings, and laboratory results of a patient.(6)

The goal of $\mathrm{CBL}$ is to prepare students for clinical practice, through the use of authentic clinical cases. It links theory to practice, through the application of knowledge to the cases, using inquiry-based learning methods. Health professional students enjoy $\mathrm{CBL}$ and think that it helps them learn better; whether this is reflected in assessment results is far from clear. However, enjoyment can lead to increased engagement and motivation for learning - a desirable and positive effect.(7) Teachers enjoys CBL too. Teachers can potentially make better use of their teaching time available, engage the students and motivate students for a more enjoyable teaching experience. $C B L$ appears to foster effective learning in small groups, possibly through the effect of more engaged learners, but also through more structured learning activities closely linked to authentic clinical practice scenarios. Online $\mathrm{CBL}$ can work well providing attention is paid to the online learning environment.

CBL is a long-established pedagogical method used in health professional education where learning activities are commonly based on patient cases. CBL in community medicine offers a unique opportunity of studying basic, social and clinical sciences in relation to the case, integrated with clinical presentations and conditions (including health and ill-health). Student learning is therefore associated with real-life situations. While many claims are made for CBL as an effective teaching and learning method, there is hardly any evidence to support its use in Community Medicine in our country. Hence this study was conducted to assess the effectiveness of $\mathrm{CBL}$ as a type of inquiry-based learning in Community Medicine.

\section{Aims \& Objectives}

1. To assess the effectiveness of Case Based Learning over the traditional teaching learning method (didactic lecture) used in Community
[Effectiveness of CBL in Community Medicine] | Annadani RR et al Medicine among second year medical undergraduates of a government medical college.

2. To assess the perceptions of second year medical undergraduates regarding Case Based Learning over the traditional teaching learning method (didactic lecture) used in the Community Medicine department in a government medical college

\section{Material \& Methods}

The present study was initiated after obtaining the Institutional Ethical Committee clearance [Ref. No. IEC/KRIMS/13/2018]. This randomized controlled study was conducted at a government medical college in coastal Karnataka over a period of six months (April 2018 to October 2018). The study participants included second year MBBS students who gave written informed consent for their participation in the study and were present during the study period. Among the 150 second MBBS students 143 students met the inclusion criteria and were randomly allocated into 2 groups (Group A with 72 students and Group B with 71 students) using simple random sampling and their roll numbers as a sampling frame. (Figure 1) Both groups were given pre-test questionnaires.

Group A was exposed to the traditional teaching method (lectures) on communicable disease of public health importance following which post-test was done using the same questionnaire. Group B was exposed to Case Based Learning (CBL) on the same topic on communicable disease. 71 students were again subdivided into ten subgroups with seven students in each group except one group which had eight students. For each subgroup a case note on communicable disease was given along with questions covering various aspects of the topic. Following the case note, students were given enough references, allowed for self-directed learning and they were free to interact with each other, the content of resource materials and with the faculty for further clarification. At the end of the session students were asked to provide solutions and allowed for large group discussion, which was facilitated by the faculty trained in medical education technologies. For unanswered questions students were provided one week's time and asked to come up with the answer in the subsequent class. They were free to approach any faculty at any time for the further clarification regarding the topic. 
INDIAN JOURNAL OF COMMUNITY HEALTH / VOL 33 / ISSUE NO 01 / JAN- MAR 2021 [Effectiveness of CBL in Community Medicine] | Annadani RR et al To assess the effectiveness of learning among both the groups a pre-test (before the intervention), posttest (immediately after the intervention) and retention test (after four weeks of intervention) was conducted in the form of Multiple-Choice Questions (MCQs). MCQ questionnaire had ten MCQs based on the various aspects of the topic. Same MCQs were used for both the groups.

Among the group $B$ who were exposed to $C B L$, their perception regarding $\mathrm{CBL}$ over the traditional method of teaching was collected using a pretested structured questionnaire that contained 12 questions covering various aspects of $\mathrm{CBL}$ over traditional teaching methods; response to questions was collected using a five-point Likert scale. Reliability coefficient (Cronbach's Alpha) of the questionnaire was 0.816 .

Data was coded and entered in MS-Excel 2010, analyzed using EpiData version-3.1.(8) Data was presented in percentage, proportions, mean and standard deviation. Paired t-test and independent ttests were applied to find out the difference in the mean scores within the group and in between the groups respectively. The $\mathrm{p}$-value $<0.05$ was considered statistically significant.

\section{Results}

The present study included a total of 143 second year MBBS students who consulted for the study. They were randomly allocated into Group A (traditional method) and Group B (CBL).

Group A had 72 students. They were in the age group of $20-22$ years. 42 (58.33\%) were males and 30 (41.67\%) were females. Group B had 71 students. They were in the age group of 20-23 years. 45 (63.38\%) were boys and $26(37.72 \%)$ were girls.

Mean pretest score of Group A was $4.13( \pm 1.82)$ and post test score of Group A was 5.64 ( \pm 1.62$)$. There was improvement in mean score of the Group $A$ in posttest which was statistically significant $(p<0.0001)$. Mean pretest score of Group B was 4.13 $( \pm 1.73)$ and post test score of Group B was 7.12 $( \pm 1.40)$. There was improvement in mean score of the group in posttest which was statistically significant $(p<0.0001)$. Mean pretest score of Group A was $4.13( \pm 1.82)$ and retention test score of Group A was $4.63( \pm 1.80)$. There was no significant improvement in mean score of the Group $A$ in retention test $(p=0.287)$. Mean retention test score of Group B was $4.63( \pm 1.80)$ and post retention test score of Group B was $6.75( \pm 1.87)$. There was improvement in mean score of the Group B in retention test which was statistically significant $(p<0.0001)$. (Table 1)

When the test scores of both the groups were compared, pre-test scores were similar. But there was a statistically significant difference observed in mean score of post-test $(p=00.0000076)$ and retention test $(p=0.000008190)$ of both groups. (Table 2)

Among group B students the perception regarding CBL was as follows: More than $70 \%$ of students agreed that Case Based Learning aroused interest in learning, encouraged group learning and team work, created interactive and supportive learning, helped in application of knowledge to clinical practice and encouraged self-directed learning. More than $50 \%$ of the students agreed that they felt confident at the end of the class, CBL was less stressful, CBL improved understanding of the topic, it helped in better retention of the topic, it helped in internal assessment/ exams and CBL can be used for other topics also. More than 70\% agreed/strongly agreed that CBL needs more time and effort compared to the traditional method. (Table 3 )

\section{Discussion}

Case Based Learning ( $C B L$ ) is a form of inquiry-based learning and fits on the continuum between structured and guided learning. Though there is evidence that health professional students enjoy CBL and it helps them learn better, whether this is reflected in assessment results is far from clear.(6) The present study fills this void by providing evidence regarding effectiveness of $C B L$ in terms of assessment results. Present study showed that CBL was more effective in teaching Community Medicine to the undergraduates which was evident from the MCQ test scores. The main principle of CBL method is student centric active learning process. The study also showed that students learn better when they are actively involved and they work in a team, which was supported by our study as the test scores improved in the post-test and retention test of CBL group. The findings of present study were similar to a study done by Nair SP et al. who found that there was a statistically significant $(p<0.0001)$ increase in the test score of the students who underwent CBL sessions as compared to that in the controls with traditional teaching learning (TL) method.(9)

In the medical field, students must remember the facts and concepts for a longer duration of time. 
Teaching learning methods must be conducive to retain the learnt knowledge for a longer duration. Case based learning helps in retention of the learnt knowledge for a longer duration of time which is evident from the present study because statistically significant improvement was seen in retention test scores compared to the traditional teaching method. Similar were the findings in a study done by Singhal $A$ where the class scores were highest for the $C B L$ sessions than didactic lectures in both the tests: one taken immediately after the sessions and second taken at an interval of 6 weeks after the completion of sessions. The difference in scores was greater in test taken after 6 weeks interval $(P<0.001)$. The study also observed that there was a decrease in the mean score of both the groups over time, but the decrease was significantly higher in the didactic lecture group than the CBL group. Similarly, in another study by Hashim et al. case-based learning method had significantly higher scores compared to tutorial method for learning process $(p<0.001)$. $(10,11)$

Most of the students gave positive feedback for Case Based learning. In the present study, most students agreed that CBL was an effective learning tool, more than $70 \%$ of students agreed that Case Based Learning aroused interest in learning, encouraged group learning and team work, created interactive and supportive learning, helped in application of knowledge to clinical practice and encouraged selfdirected learning. This was lesser in comparison with a study in which $98 \%$ of the students agreed that CBL motivated them to study, experienced more enjoyment with $\mathrm{CBL}$ as compared to didactic lectures, facilitated interaction between the staff and students through $\mathrm{CBL}$ discussion sessions, CBL helped in improving their diagnostic skills and lateral thinking.(9)

In present study, more than $50 \%$ of the students agreed that they felt confident at the end of the class, CBL was less stressful, CBL improved understanding of the topic, it helps in better retention of the topic, it helps internal assessment/ exams and CBL can be used for other topics also. This is comparable with a study done by Singh PR et al. who found that $51 \%$ felt CBL will help them perform better in University Exams, $84 \%$ of them felt that this exposure would be of great help in the future also. Overall, the students enjoyed the learning session with the CBL method.(12) Similar were findings in various other studies. $(13,14,15,16)$
[Effectiveness of CBL in Community Medicine] | Annadani RR et al

\section{Conclusion}

Case based learning was effective over the traditional method in teaching and learning Community Medicine. Statistically significant difference was observed in posttest and retention test scores between the groups. Students perceived that $\mathrm{CBL}$ aroused interest and encouraged selfdirected learning.

\section{Recommendation}

Case based learning is a student centric learning method that can be included in teaching Community Medicine to medical undergraduates. Inclusion of $\mathrm{CBL}$ as a TL method in Community Medicine shall help students improve their academic performance because of improved retention levels (Community Medicine teaching is spread across phases, a first year MBBS student begin learning Community Medicine in first year but takes University Exams in third year MBBS). Further studies studying retention level across the phases of MBBS shall be helpful in adding evidence to the present one.

\section{Limitation of the study}

The study included only students belonging to second year MBBS students though Community Medicine is learnt from first year to third year MBBS and again during internship.

\section{Relevance of the study}

Presently, faculties in most of the medical colleges in India teach Community Medicine using traditional teaching learning methods with few exceptions. This makes the medical undergraduates less engaged in one of the important subjects (Community Medicine) that spans over entire MBBS curriculum (Phase I, II, Phase III Part I and Internship). To overcome this shortcoming, CBL in community medicine offers a unique opportunity of studying basic, social and clinical sciences in relation to the case, integrated with clinical presentations and conditions (including health and ill-health). Student learning is therefore associated with real-life situations. This study provides evidence regarding the effectiveness of CBL that supports its use in teaching and learning Community Medicine in medical college that shall be helpful for both students and faculties particularly with recently rolled out CBME curriculum that insists on more hours of student-centric and self-directed learning. 
[Effectiveness of CBL in Community Medicine] | Annadani RR et al

\section{Authors Contribution}

Both the authors (RAR and MU) have contributed equally to the design and implementation of the research, to the analysis of the results and to the writing of the manuscript.

\section{Acknowledgement}

We acknowledge Medical Education Unit, KIMS, Karwar for providing valuable suggestions during conducting the study. We also acknowledge $\mathrm{MCl}$ Nodal Centre for Medical Education Technologies (MET), Department of Medical Education (DOME), JNMC Belagavi, Karnataka for providing the valuable suggestions during the study, that was a part of Advance Course in Medical Education (ACME) approved by $\mathrm{MCl}$.

\section{References}

1. Walker SE. Active learning strategies to promote critical thinking. J Athl Train. 2003;38(3):263-7. PMID: 16558680; PMCID: PMC233182.[PubMed].

2. Jaques D. Teaching small groups. BMJ. 2003;326(7387):492-4. doi: 10.1136/bmj.326.7387.492. PMID: 12609949; PMCID: PMC1125374.[PubMed]

3. Russel AT, Comello RJ, Wright DL. Teaching strategies promoting active learning in healthcare education. Journal of Education and Human Development. 2007.

4. Kamran A, Rehman R, Iqbal A. Importance of clinically oriented problem solving tutorials (COPST) in teaching of physiology. Rawal Med J. 2011;36(3):232-6.

5. Surapaneni KM. The Effect of Integrated Teaching with Case Based Learning (CBL) In the Biochemistry of Undergraduate Medical Curriculum. J. Clin Diagn Res. 4:3058-3063

6. Thistlethwaite JE, Davies D, Ekeocha S, Kidd JM, MacDougall C, Matthews P, Purkis J, Clay D. The effectiveness of case-based learning in health professional education. A BEME systematic review: BEME Guide No. 23. Med Teach. 2012;34(6):e421-44. doi: 10.3109/0142159X.2012.680939. PMID: 22578051. [PubMed].

7. BEME Spotlight 23 The effectiveness of case-based learning in health professional education. A BEME systematic review: BEME Guide No. 23 Jill Elizabeth Thistlethwaite, David Davies, Samilia Ekeocha, Jane M. Kidd, Colin MacDougall, Paul Matthews, Judith Purkis, Diane Clay.

8. Lauritsen JM. (Editor) EpiData Data Entry, Data Management and basic Statistical Analysis System. Odense Denmark, EpiData Association, 2000-2008. Available from http://www.epidata.dk.

9. Nair SP, Shah T, Seth S, Pandit N, Shah GV. Case based learning: a method for better understanding of biochemistry in medical students. J Clin Diagn Res. 2013;7(8):1576-8. doi: 10.7860/JCDR/2013/5795.3212. Epub 2013 Aug 1. PMID: 24086843; PMCID: PMC3782900.[PubMed]

10. Singhal A. Case-based Learning in Microbiology: Observations from a North West Indian Medical College. Int J Appl Basic Med Res. 2017;7(Suppl 1):S47-S51. doi: 10.4103/ijabmr.IJABMR_146_17. PMID: 29344458; PMCID: PMC5769171. [PubMed].

11. Hashim R, Azam N, Shafi M, Majeed S, Ali S. Perceptions of undergraduate medical students regarding case based learning and tutorial format. J Pak Med Assoc. 2015;65(10):1050-5. PMID: 26440831.[PubMed].

12. Singh $P R, B$ hatt $R$. Introduction of case based learning for teaching anatomy in a conventional medical school. J Ant Soc India 2011;60(2):232-5

13. Ciraj AM, Vinod P, Ramnarayan K. Enhancing active learning in microbiology through case based learning: experiences from an Indian medical school. Indian J Pathol Microbiol. 2010;53(4):729-33. doi: 10.4103/0377-4929.72058. PMID: 21045402.[PubMed]

14. Armbruster $P$, Patel $M$, Johnson $E$, Weiss $M$. Active learning and student- centered pedagogy improve student attitudes and performance in introductory biology. CBE Life Sci Educ. 2009 Fall;8(3):203-13. doi: 10.1187/cbe.09-03-0025. PMID: 19723815; PMCID: PMC2736024.[PubMed]

15. Chan WP, Hsu CY, Hong CY. Innovative "Case-Based Integrated Teaching" in an undergraduate medical curriculum: development and teachers' and students' responses. Ann Acad Med Singap. 2008;37(11):952-6. PMID: 19082203.[PubMed]

16. Tathe SS, Singh AL. Case based lectures versus conventional lectures for teaching Medical Microbiology to undergraduate students. Int J Cur Res Rev. 2014;6:3541.

\section{Tables}

\section{TABLE 1 COMPARISON OF TEST MEAN SCORES WITHIN THE GROUPS}

\begin{tabular}{|c|l|l|l|l|}
\hline Groups & Pretest (Mean \pm SD) & Posttest (Mean \pm SD) & t value & p-value \\
\hline Group A & $4.13( \pm 1.82)$ & $5.64( \pm 1.62)$ & -8.577 & $<0.0001^{*}$ \\
\hline Group B & $4.13( \pm 1.73)$ & $7.12( \pm 1.40)$ & -4.389 & $<0.0001^{*}$ \\
\hline & Pretest (Mean \pm SD) & Retention test (Mean \pm SD) & t value & p-value \\
\hline Group A & $4.13( \pm 1.73)$ & $4.63( \pm 1.80)$ & -1.155 & 0.287 \\
\hline Group B & $4.13( \pm 1.73)$ & $6.75( \pm 1.87)$ & -7.502 & $<0.0001^{*}$ \\
\hline \multicolumn{2}{l}{ Note: ${ }^{*}$ statistically significant } & & & \\
\hline
\end{tabular}




\begin{tabular}{|c|c|c|c|c|}
\hline Test & Group A (Mean \pm SD) & Group B (Mean \pm SD) & $t$ value & $p$-value \\
\hline Pretest & $4.13( \pm 1.82)$ & $4.13( \pm 1.73)$ & 0.0 & $>0.99$ \\
\hline Posttest & $5.64( \pm 1.62)$ & $7.12( \pm 1.40)$ & -4.76 & $0.0000076 *$ \\
\hline Retention test & $4.63( \pm 1.80)$ & $6.75( \pm 1.87)$ & -4.84 & $0.000008190^{*}$ \\
\hline \multicolumn{5}{|c|}{ Note: *statistically significant } \\
\hline
\end{tabular}

\section{TABLE 3 PERCEPTION OF STUDENTS REGARDING CASE BASED LEARNING (CBL) OVER TRADITIONAL} METHODS. $(\mathrm{N}=71)$

\begin{tabular}{|c|c|c|c|c|c|c|}
\hline $\begin{array}{l}\text { Sl. } \\
\text { No. }\end{array}$ & Student's perception & $\begin{array}{l}\text { Strongly } \\
\text { Agree* }\end{array}$ & Agree* & Neutral* & Disagree* & $\begin{array}{l}\text { Strongly } \\
\text { Disagree* }\end{array}$ \\
\hline 1. & Aroused interest in learning & 5.3 & 71.1 & 15.8 & 7.9 & 0 \\
\hline 2. & Encouraged group learning \& teamwork & 18.4 & 65.8 & 15.8 & 0 & 0 \\
\hline 3. & I felt confident at the end of session & 0 & 42.1 & 36.8 & 18.4 & 2.6 \\
\hline 4. & $\begin{array}{l}\text { Creates Interactive \& supportive learning } \\
\text { environment }\end{array}$ & 21.1 & 60.5 & 13.2 & 5.3 & 0 \\
\hline 5. & Application of knowledge to clinical practice & 10.5 & 68.4 & 21.1 & 0 & 0 \\
\hline 6. & Consumed more time compared to lectures. & 34.2 & 44.7 & 15.8 & 5.3 & 0 \\
\hline 7. & CBL was less stressful & 13.2 & 36.8 & 26.3 & 23.7 & 0 \\
\hline 8. & $\mathrm{CBL}$ improved understanding of the topic & 7.9 & 44.7 & 31.6 & 15.8 & 0 \\
\hline 9. & Encouraged self-directed learning & 13.2 & 57.9 & 28.9 & 0 & 0 \\
\hline 10. & Better retention and recall of the knowledge & 5.3 & 47.4 & 34.2 & 13.2 & 0 \\
\hline 11. & CBL will help in internal assessment/exams & 2.6 & 36.8 & 31.6 & 21.1 & 7.9 \\
\hline 12. & CBL can be done for other topics also. & 7.9 & 44.7 & 36.8 & 7.9 & 2.6 \\
\hline
\end{tabular}

\section{Figures}

FIGURE 1 CONSOLIDATED STANDARDS OF REPORTING TRIALS (CONSORT) FLOW DIAGRAM DISPLAYING THE PROGRESS OF ALL PARTICIPANTS THROUGH THE STUDY CONSORT 2010 Flow Diagram

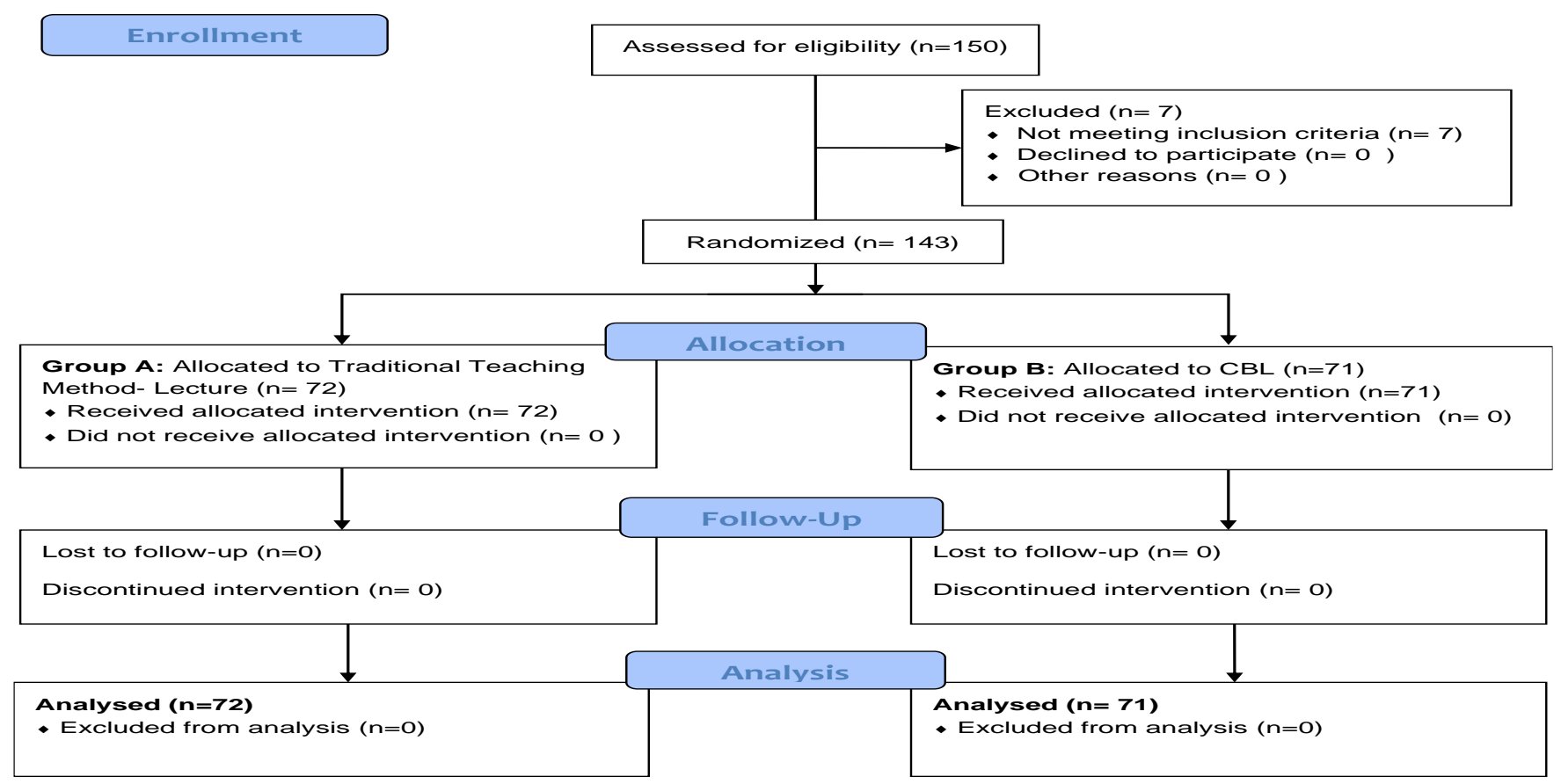

